\title{
Health Systems in Australia and Four Other Countries: choices and challenges
}

\author{
J M Martins
}

\begin{abstract}
The purpose of health systems is the pursuit of healthy lives. The performance of the Australian health system over the last decade is compared with the United Kingdom and its three other offshoots: the United States, Canada and New Zealand. In the first instance, system performance is assessed in terms of threats to healthy lives from risk factors and changes that have taken place during the decade. In view of the emphasis of the five systems on the return to health after trauma and illness, and the human-resource intensity of health services, an appraisal is made of changes in the number of the major health professionals in relation to the growing populations. Then related changes in hospital, medical practitioner and dentist services are assessed. Changes in pharmaceutical drug prescriptions in Australian are also examined. The levels of national expenditures arising from the provision health services are then considered in the context of the costs of
\end{abstract}

administration of the varied organisational modes, use of expensive medical technologies, pharmaceutical drug consumption and remuneration of health professionals. Finally, health outcomes in Australia and the other four countries are assessed in accordance with their human development level, life expectancy, potential years of life lost from different causes, as well as healthy life expectancies. Further, gaps in health and life expectancy of Indigenous people in the United States, Canada, New Zealand and Australia are reviewed, as well as health and survival inequalities among people in different social strata in each country.

Abbreviations: GDP - Gross Domestic Product; HDI - Human Development Index.

Key words: health systems; health resources and services; health outcomes.

\section{Jo M Martins \\ Centre for Health Policy and Management \\ and Macquarie University \\ Sydney, New South Wales, Australia \\ Correspondence: \\ jmartins@tpg.com.au}

\section{Means to an end}

Health systems are about choices and challenges in the pursuit of healthy lives. In the last decade, changes have taken place in the Australia's health system [1] which reflect opportunities gained and lost and choices made. This had an impact on the effectiveness and efficiency of the system, and also on equity in outcomes. As contrasts can make system features more apparent, the Australian experience will be examined in comparison with those of the United Kingdom and its other 'offshoots': United States, Canada and New Zealand. This approach requires a reasonable degree of consistency in definitions across countries and measurement over time. To this end, the following analysis will rely, as much as possible, on data kept by international organisations that attempt to reconcile the various definitions adopted by different countries.

\section{Health promotion and threats}

An important purpose of health systems is to manage behaviours and conditions that affect health. A number of relevant factors have been identified and there is data to assess trends and their relative importance. Nevertheless, according to Shaw... Whether we refer to mortality, morbidity or self-reported health, and whichever indicator of socioeconomic position we employ - income, class housing tenure, deprivation or education - we find that those who are worse off socio-economically have worse health. [2] 
Table 1: Income per head of population in Australia, New Zealand, Canada, United States and United Kingdom, 2001 and 2011

\begin{tabular}{|l|c|c|c|c|}
\hline \multirow{2}{*}{ counTRY } & \multicolumn{3}{|c|}{ GDP PER CAPITA PPP \$ } & $\begin{array}{c}\text { INEQUALITY } \\
\text { INGHES TO LOWEST } \\
\text { INCOME QUINTILE }\end{array}$ \\
\cline { 2 - 5 } & 2001 & 2011 & $\begin{array}{c}2001-2011 \\
\text { GROWTH \% }\end{array}$ & 17.8 \\
Australia & 35,443 & 41,763 & 12.8 & 5 \\
New Zealand & 29,020 & 32,737 & 10.2 & 5 \\
Canada & 37,712 & 41,565 & 8.3 & 8 \\
United States & 45,978 & 49,782 & 8.7 & 6 \\
\hline
\end{tabular}

Note: GDP per capita is the average gross domestic product per head of population expressed in purchasing power parities in constant 2011 international dollars. Inequality highest and lowest income quintiles is the times that the top $20 \%$ of the population earn more than the lowest $20 \%$. Sources: WB [3] OECD. [4] Computations made by the author.

Income is important to get food, shelter and other necessities for a healthy life to a point, beyond which it has a lower impact on health. Income inequalities represent not only differences of income but are surrogates for social groups that experience differences in health and survival. [2] Australia and the other four countries are among the higher income countries in the world. Australian gains in income per capita were greater than those in the other countries during the decade 2001-2011. The United States and the United Kingdom had the lowest rates of income growth. However, at the end of the decade, New Zealand had an income per capita of only $66 \%$ that of the United
States. Australia and Canada had about the same income level, but lower than the United States, while the United Kingdom income per capita was only just above that of New Zealand. In view of the relatively high average income of these countries, a feature of relevance is the inequality between the highest and lowest income quintiles that is about five times in Australia and Canada, but six and eight in the United Kingdom and United States respectively (Table 1). This points to constraints of those in the lowest income quintiles to access basic living needs and possible impact on their health status and survival.

Table 2: Employment and hours at work in Australia, New Zealand, Canada, United States and United Kingdom, circa 2013

\begin{tabular}{|c|c|c|c|}
\hline COUNTRY & EMPLOYMENT \% & HOUR WORK & LONG HOURS OF WORK \\
\hline Australia & 73 & 1,693 & 14 \\
\hline New Zealand & 73 & 1,762 & 13 \\
\hline Canada & 72 & 1,702 & 4 \\
\hline United States & 67 & 1,776 & 11 \\
\hline United Kingdom & 70 & 1,625 & 12 \\
\hline OECD Average & 66 & 1,776 & 9 \\
\hline
\end{tabular}

Note: Employment is the percentage of people aged 15-64 years of age with paid jobs. Hours of work are the number of hours worked per year. Long hours of work are the percentage of employees who work very long hours.

Source: OECD. [4] 
Employment fulfils a number of functions concerned with economic security of relevance to a healthy life. It also entails occupational involvement and a degree of social interaction. Nevertheless, it has health risks that affect the balance between work and other interests such as the time dedicated to family, housework and recreation. Consistent data for the decade under review and across countries is scarce. Available information indicates that Australians spent about the same working hours as Canadians, more than people in the United Kingdom, but less than those in New Zealand and the United Sates. However, the proportion who spent very long hours at work in Australia was the highest but about the same as in New Zealand. Canadian workers had the lowest level of very long hours worked (Table 2). Although on average, the number of hours worked in Australia is not as high as that in the United States, a higher proportion spent very long hours at work and risked an imbalance between work and family, and had less time for exercise and social interaction outside the work place.
As occupations require lesser physical exertion and leisure time is of a more sedentary nature, physical exercise is a health concern. The World Health Organization estimated that in 2010 a quarter (23.8\%) of adults in Australia did insufficient physical activity to be healthy. This was about the same level as that of Canada and much less than the level in the United States, United Kingdom and New Zealand (Table 5). Further, surveys of sport and physical recreation in Australia show that participation declined between 200506 and 2009-10 among people 15 years of age and over. [7] The level of obesity in Australia of about one quarter (26.8\%) of the adult population was similar to that of Canada, New Zealand and the United Kingdom, but lower than that in the United States (Table 5). The degree of obesity and overweight in Australia has risen substantially since 1995. [8]

Table 3: Physical activity (2010) and obesity (2008), Australia, New Zealand, Canada, United States and United Kingdom

\begin{tabular}{|l|c|c|}
\hline COUNTRY & COUNTRY INSUFFICIENT PHYSICAL ACTIVITY & OBESITY \\
\hline Australia & 23.8 & 26.8 \\
New Zealand & 39.8 & 28.5 \\
Canada & 23.2 & 26.2 \\
United States & 32.4 & 33.0 \\
United Kingdom & 37.3 & 26.9 \\
\hline
\end{tabular}

Note: Insufficient physical activity is the percentage age-standardised prevalence in adults 18 years and over in 2010. Obesity is the percentage of adults 18 years of age and over who were obese in 2008.

Sources:WHO. [5,6]

Table 4: Unemployment and divorce in Australia, New Zealand, Canada, United States and United Kingdom, 2001 and 2011

\begin{tabular}{|l|c|c|c|c|}
\hline \multirow{2}{*}{ COUNTRY } & \multicolumn{2}{|c|}{ UNEMPLOYMENT RATE \% } & \multicolumn{2}{|c|}{ CRUDE DIVORCE RATE } \\
\cline { 2 - 5 } & $2000-2002$ & $2009-2011$ & 2001 & 2011 \\
\hline Australia & 6.5 & 5.3 & 2.8 & 2.2 \\
New Zealand & 5.6 & 6.4 & 2.5 & 1.9 \\
Canada & 7.2 & 7.9 & 2.1 & 2.1 \\
United States & 4.8 & 9.3 & 4.0 & 3.6 \\
United Kingdom & 5.2 & 7.8 & 2.7 & 2.1 \\
\hline
\end{tabular}

Note: Unemployment rate is the percentage of people in the labour force who are seeking employment. Crude divorce rate is the number of divorces per thousand people.

Source: OECD. [9] 
The review period includes the Global Financial Crisis that led to substantial rises in unemployment in most countries with associated insecurity and other emotional impact. Australia fared better than the other countries. Unemployment in Australia declined in the period under review while that of the other four countries rose. Divorce is a source of insecurity and emotional distress. Its incidence declined in Australia and most other countries. The lowest levels prevailed in Canada and New Zealand, while the United States had the highest divorce rate (Table 4). However, this indicator has become of a lesser significance because of the increasing proportion of unions that do not involve 'marriage' in its full legal sense.

The use of alcohol and tobacco affects health. Substantial progress was made in Australia and the other four countries in reducing tobacco use, especially in New Zealand and the United Kingdom. However, alcohol use in 2011 remained at about the 2001 level (Table 5). The fall in tobacco use has a beneficial impact on the incidence of respiratory and heart disease and related mortality, as well as physical conditioning, while high levels of alcohol intake continue to be sources of social stress and threats to health.

Examination of available evidence suggests that Australia did better at containing its consumption of sugar, that is much lower than that of the United Sates, than of fat consumption that rose substantially in the 10-year period 2001-2011, to bring it close to the level in Canada, and well above New Zealand and the United Kingdom. The trend was for greater consumption of fats with the exception of the United Kingdom. Australia also did not do well in its consumption of either vegetables or fruit both below average. With the exception of the United Kingdom, with a low level of vegetable consumption, there was a tendency towards lower consumption of vegetables in the decade under review (Table 6), This analysis indicates the challenges to the health system of how to promote more balanced nutrition and so avoid obesity and other deleterious health conditions.

Table 5: Alcohol and tobacco use in, Australia, New Zealand, Canada, United States and United Kingdom, 2001 and 2011

\begin{tabular}{|l|c|c|c|c|}
\hline \multirow{2}{*}{ COUNTRY } & \multicolumn{2}{|c|}{ ALCOHOL } & \multicolumn{2}{|c|}{ TOBACCO } \\
\cline { 2 - 5 } Australia & 2001 & 2011 & 2001 & 1,009 \\
New Zealand & 10 & 10 & 1,308 & 771 \\
Canada & 9 & 10 & 1,126 & 1,020 \\
United States & 8 & 8 & 1,429 & 955 \\
United Kingdom & 8 & 9 & 1,212 & 1,113 \\
\hline
\end{tabular}

Note: Alcohol in litres per capita people 15 years of age and over. Tobacco in grams per capita, people 15 years of age and over. Source: OECD. [9]

Table 6. Nutrition in Australia, New Zealand, Canada, United States and United Kingdom, 2001 and 2011

\begin{tabular}{|l|c|c|c|c|c|r|r|r|}
\hline \multirow{2}{*}{ CouNTRY } & \multicolumn{2}{|c|}{ FAT } & \multicolumn{2}{c|}{ SUGAR } & \multicolumn{2}{c|}{ VEGETABLES } & \multicolumn{2}{c|}{ FRUIT } \\
\cline { 2 - 9 } Australia & 2001 & 2011 & 2001 & 2011 & 2001 & 2011 & 2001 & 2011 \\
New Zealand & 138 & 153 & 46 & 47 & 105 & 96 & 97 & 94 \\
Canada & 112 & 125 & 60 & 55 & 142 & 113 & 116 & 94 \\
United States & 147 & 150 & 53 & 49 & 121 & 114 & 124 & 129 \\
United Kingdom & 155 & 162 & 68 & 61 & 124 & 113 & 113 & 97 \\
\hline
\end{tabular}

Note: Fat in grams per capita per day. Sugar in kilograms per capita per year. Vegetables in kilograms per capita per year. Fruit in kilograms per capita per year.

Source: OECD. [9] 
With the exception of the use of tobacco where substantial lessening of use was achieved, the evidence is that the health system is not coping well with risk factors that have a cumulative effect over the life cycle and which will have an impact on the prevalence of noncommunicable disease, related disability and possible premature mortality. This also implies a greater demand for health service resources to deal with the aftermath of these conditions as current cohorts age.

\section{Essential human resources}

Health systems are essentially about the people who work to keep or return other people to health. The tendency is for the health system to focus on health services that manage trauma, illness and restoration of health. This is where most human resources in the system are employed. Most nurses work in hospitals while medical practitioners, pharmacists and dentists work in hospitals but tend to practise mostly in the community, in the private sector, in the five countries.

Most health professionals are nurses. Over the 10-year period 2001-2011, the number of nurses in Australia kept pace with population growth at about 10 per thousand people. This was the highest ratio in the five countries. The number of nurses in New Zealand grew faster to catch up with the level in Australia by the end of the period. In Canada and the United States, the number of nurses also rose per head of population, but at a lower level, but the ratio declined in the United Kingdom (Table 7).

The number of doctors rose substantially in Australia from 2.6 per thousand people in 2001 to 3.3 in 2011. This was and continued to be the highest level in the five countries, in spite of increments in the number of doctors in relation to the population in the other four countries, especially in the United Kingdom during the period (Table 7).

The number of pharmacists in Australia per head of population showed a slight increase to 0.9 per thousand people, but remained close to that in Canada and United Sates and above the level in New Zealand. Similarly, the number of dentists just stayed ahead of population growth at 0.6 per thousand people but at a steady low rate (Table 7).

Table 7: Nurses, medical practitioners, pharmacists and dentist in Australia, New Zealand, Canada, United States and United Kingdom, 2001 and 2011

\begin{tabular}{|c|c|c|c|c|}
\hline \multirow[b]{2}{*}{ COUNTRY } & \multicolumn{4}{|c|}{ NUMBER PER 1,000 PEOPLE } \\
\hline & NURSES & MEDICAL & PHARMACISTS & DENTISTS \\
\hline & \multicolumn{4}{|c|}{2001} \\
\hline Australia & 10.0 & 2.6 & 0.7 & 0.5 \\
\hline New Zealand & 9.0 & 2.2 & 0.6 & 0.4 \\
\hline Canada & 7.5 & 2.1 & 0.8 & 0.5 \\
\hline United States & 7.8 & 2.4 & 0.8 & 0.6 \\
\hline \multirow[t]{2}{*}{ United Kingdom } & 9.3 & 2.0 & NA & 0.5 \\
\hline & \multicolumn{4}{|c|}{2011} \\
\hline Australia & 10.1 & 3.3 & 0.9 & 0.6 \\
\hline New Zealand & 10.1 & 2.7 & 0.7 & 0.5 \\
\hline Canada & 9.3 & 2.5 & 0.9 & 0.6 \\
\hline United States & 8.6 & 2.5 & 0.9 & 0.6 \\
\hline United Kingdom & 8.6 & 2.7 & NA & 0.5 \\
\hline
\end{tabular}

Note: The figures are for the years or the closest dates available from OECD to enhance comparability, but the figures for nurses in the United Sates are not available from that source and were estimates from data from the US Department of Health and Human Services.

Sources: OECD [9] and DHHS. [10] 
Over the period, with the exception of nurses in the United Kingdom, there was a rising ratio of health professionals servicing growing populations, especially in Australia but also in the other United Kingdom offshoots. A remarkable change was the large increase in doctors in most of the five countries. The substantial increment in Australia was accompanied by a growing proportion of female medical practitioners during the period, who tend to work shorter hours than males, [11] possibly to keep a balance between work and family life.

\section{Major services provided}

Australia and New Zealand had the largest utilisation of inpatient care per head of population among the five countries, respectively 158 and 160 inpatient admissions per thousand people in 2011. This was supported by their larger ratio of nurses to population. Nevertheless, Canada also with a high ratio of nurses had the lowest number of admissions per head of population $(84 / 1,000)$ of all the five countries. The United Sates had the second lowest rate of admissions $(119 / 1,000)$ in 2011 . The utilisation of inpatient services per capita, that declined during the period 2001-2011 in New Zealand, Canada and United States, and stayed at about the same level in Australia and the United Kingdom (Table
8) was associated with a rising and additional same-day admissions that were more than the inpatient admissions in Australia - many in stand-alone private surgeries - and New Zealand. [16-19]

Doctor visits per head of population in Australia more than kept pace with population growth at 6.7 visits per capita in 2011. This was higher than the use of doctor services per capita in the United Kingdom, United States and New Zealand, but lower than in Canada (7.8 visits) (Table 8) with a substantially lower number of doctors per head of population.

Visits to dentists varied substantially in the five countries with Australia having a slightly higher number per head of population (1.5) than Canada (1.3) in 2011. This was about the level of 2001. The number of visits stayed at a lower level in both the United Sates and the United Kingdom (Table 8).

Information on the volume of pharmaceutical prescriptions in the other four countries to compare with that in Australia is not available in a consistent manner. The number of prescriptions in Australia rose from 7.6 per head of population in 2001 to 8.4 in 2011. [20]

Table 8: Doctor and dentist visits, hospital admissions in Australia, New Zealand, Canada, United States and United Kingdom, 2001 and 2011

\begin{tabular}{|c|c|c|c|}
\hline COUNTRY & $\begin{array}{l}\text { DOCTOR VISITS } \\
\text { PER CAPITA }\end{array}$ & $\begin{array}{l}\text { HOSPITAL ADMISSIONS } \\
\text { PER } 1,000 \text { PEOPLE }\end{array}$ & $\begin{array}{l}\text { DENTISTS VISITS } \\
\text { PER CAPITA }\end{array}$ \\
\hline & \multicolumn{3}{|c|}{2001} \\
\hline Australia & 6.4 & 155 & 1.4 \\
\hline New Zealand & 4.0 & 206 & NA \\
\hline Canada & 7.5 & 91 & 1.3 \\
\hline United States & 4.1 & 124 & 1.1 \\
\hline \multirow[t]{2}{*}{ United Kingdom } & 5.1 & 133 & 0.7 \\
\hline & \multicolumn{3}{|c|}{2011} \\
\hline Australia & 6.7 & 158 & 1.5 \\
\hline New Zealand & 3.7 & 160 & NA \\
\hline Canada & 7.8 & 84 & 1.3 \\
\hline United States & 4.0 & 119 & 0.9 \\
\hline United Kingdom & 5.9 & 134 & 0.8 \\
\hline
\end{tabular}

Note: The data is mostly from OECD collections but also from country sources when OECD data was not available for some years. (NA.) means not available.

Sources: OECD; [12-14] DHHS; [10] MOHNZ; [15-16] AlHW; [18-19] 
In this comparison of service use, the Australian health system provided a higher level of services per head of population that more than kept pace with its large population growth. A major contrast is the utilisation of hospital and doctor visits, in two similar systems in Australia and Canada. The lowest level of hospital admissions in Canada compares with the highest level of admissions in Australia (and New Zealand), while the highest level of doctor visits in Canada compares with a lower level in Australia, and the lowest level in New Zealand. A major difference between the Australian and Canadian systems is the growing role of private hospitals in Australia and the static number of them in Canada. A factor in the lower use of doctor visits in Australia than in Canada could be the large out-of-pocket copayments in Australia. [13]

\section{Health expenditure}

Health expenditure levels in Australia and the other four countries are influenced by a number of factors, including the human and other resources available, the way in which these resources are organised and used, as well as the relative prices paid for them. Thus, a higher level of expenditure is not necessarily translated into a higher level of access and use of health services. The five countries experiences are a good illustration of this.

Table 9: Health expenditure as a proportion of gross domestic product and public funding in Australia, New Zealand, Canada, United States and United Kingdom, 2001 and 2011

\begin{tabular}{|c|c|c|}
\hline COUNTRY & $\begin{array}{l}\text { HEALTH EXPENDITURE } \\
\% \text { GDP }\end{array}$ & $\begin{array}{c}\text { PUBLIC EXPENDITURE } \\
\% \text { OF CURRENT EXPENDITURE }\end{array}$ \\
\hline & \multicolumn{2}{|c|}{2001} \\
\hline Australia & 8.1 & 69 \\
\hline New Zealand & 7.6 & 77 \\
\hline Canada & 9.1 & 71 \\
\hline United States & 13.8 & 44 \\
\hline \multirow[t]{2}{*}{ United Kingdom } & 6.9 & 82 \\
\hline & \multicolumn{2}{|c|}{2011} \\
\hline Australia & 8.9 & 67 \\
\hline New Zealand & 10.3 & 80 \\
\hline Canada & 11.2 & 71 \\
\hline United States & 17.7 & 49 \\
\hline United Kingdom & 9.4 & 80 \\
\hline
\end{tabular}

Note: Health expenditure includes capital expenditure, and is expressed as a percentage of gross domestic product. Public expenditure is the percentage of current (excludes capital) expenditure funded by the public sector.

Sources: OECD. $[9,13]$ Computations made by the author.
Health expenditure as a proportion of gross domestic product (GDP) rose during the period in all five countries. Australia experienced the lowest increment to $8.9 \%$ of GDP in 2011. This was about half (45.7\%) that of the United States at $17.7 \%$ of GDP in that year, and below that of Canada (11.2\%), New Zealand (10.3\%) and slightly lower than the United Kingdom (9.4\%). Among the five, the United States was the country without universal coverage of core health services mandated by the government and relied on a mixture of schemes for the poor and old people funded by the public sector and private health insurance. Australia and Canada had similar coverage schemes, even if highly fragmented in the case of Australia, that covered core services such as medical practitioner and hospitals services. The United Kingdom and New Zealand have national health schemes that also cover core services. [13] Although some form of private health insurance prevails in the five countries, it is more prevalent in the United States. Accordingly, the United States spent about 7\% of its health expenditure on administration (mostly of private health insurance) considerably more than Australia's 2\%, Canada 3\% and New Zealand 3\%. [10,21-23] This indicates that greater coverage of core health services and greater proportion of public funding did not lead to a higher level 
of expenditures or higher costs in administration. The evidence is also that in spite of its fragmentation of funding mechanisms, including private health insurance, Australia had a low level of administrative costs.

Expenditure on some modes of medical technology is another area where Australia differed considerably from the United States and to a lesser extent with Canada with an impact on the level of health expenditure. The use of expensive magnetic resonance tomography (MRI) was about four times higher in the United States than Australia and that of computed tomography (CT) about three times higher in 2011. However, the use of these two medical technologies in Australia was much greater than the use in New Zealand which had the lowest rate of use of these technologies among the five countries. Australian use was also lower than the levels in Canada (Table 10).
The prescription of pharmaceutical drugs is an important element in the management of health conditions and makes a significant contribution to health expenditure in each country. In addition to the volume, prices tend to vary substantially among countries thus making a difference to levels of expenditure. The United Sates known for its high price of drugs spent about twice as much on drugs as a proportion of GDP (2.1\%) than New Zealand (1.0\%) in 2011. Australia spent about $1.4 \%$ while Canada (1.9\%) was close to the United States (Table 11). No comparable information is available for the United Kingdom. Although the level of spending as a proportion of GDP was unequal in Australia, Canada and the United Sates in 2001, the level of expenditure in all countries increased by about $0.4 \%$ of GDP in the 10 year period. [12-13] This meant that in proportional terms the increment was higher in Australia than the other two countries.

Table 10: Use of some medical technologies Australia, New Zealand, Canada, United States and United Kingdom, 2011

\begin{tabular}{|l|c|c|}
\hline \multirow{2}{*}{ COUNTRY } & MRI & CT \\
\hline \multirow{2}{*}{ Australia } & \multicolumn{2}{|c|}{ EXAMS PER 1,000 PEOPLE - AUSTRALIA = 1.00 } \\
\cline { 2 - 3 } New Zealand & 1.00 & 1.00 \\
Canada & 0.17 & 0.26 \\
United States & 2.08 & 1.40 \\
United Kingdom & 4.29 & 3.01 \\
\hline
\end{tabular}

Note: MRI is exams of magnetic resonance imaging per thousand people. CT is exams of computed tomography. Both are expressed as a ratio to the exams in Australia, and exams in Australia equal 1.00 (Australia: MRI exams $=24$ exams and CT exams $=91$ ).

Source: OECD. [13] Computations made by the author.

Table 11: Expenditure on pharmaceutical drugs in Australia, New Zealand, Canada and United States, 2011

\begin{tabular}{|l|c|c|}
\hline COUNTRY & $\begin{array}{c}\text { PHARMACEUTICAL EXPENDITURE } \\
\text { PER CAPITA - AUTRALIA }=1.00\end{array}$ & $\begin{array}{c}\text { PHARMACEUTICAL EXPENDITURE } \\
\text { \% GDP }\end{array}$ \\
\hline Australia & 1.00 & 1.4 \\
New Zealand & 0.48 & 1.0 \\
Canada & 1.19 & 1.9 \\
United States & 1.68 & 2.1 \\
\hline
\end{tabular}

Note: Pharmaceutical expenditure is the average per head of population in purchasing power parities 2011 international dollars, when Australia (\$587) equals 1.00; and pharmaceutical expenditure is expressed as a percentage of gross domestic product.

Source: OECD. [13] Computations made by the author. 
Table 12: Remuneration of hospital nurses in Australia, New Zealand, Canada, United States and United Kingdom, 2011

\begin{tabular}{|l|c|}
\hline COUNTRY & HOSPITAL NURSE REMUNERATION - AUSTRALIA $=1.00$ \\
\hline Australia & 1.00 \\
New Zealand & 0.88 \\
Canada & 0.91 \\
United States & 1.25 \\
United Kingdom & 0.79 \\
\hline
\end{tabular}

Note: Hospital nurse yearly remuneration is the yearly average in purchasing power parities 2011 international dollars, when Australia $(\$ 80,000)$ equals 1.00 .

Source: OECD. [13] Computations made by the author.

Hospital nurses are the largest single resource in the health system of the five countries. Health expenditure is not only impacted by the relative number employed but also by their remuneration levels. In 2011, the average remuneration of hospital nurses in the United Kingdom was about two thirds (63\%) that earned in the United States. Smaller but still substantial differences applied in Australia (80\%), Canada (73\%) and New Zealand (70\%). [13]

Another major factor in the different levels of health expenditure is the rate of remuneration of medical practitioners. A study carried out for the OECD showed that the remuneration of medical general practitioners in Canada was $73 \%$ that in the United States, and that in the United Kingdom 82\%. The difference was higher in the case of specialist remuneration that was about $64 \%$ in the United Kingdom and $67 \%$ in Canada. The number of hours worked was similar in the United States and Canada so did not explain differences in earnings. [24] Other information indicates that medical specialists in Australia earn about the same as those in Canada and that general practitioners earn possibly less. [25] This implies that the relatively larger number of medical practitioners in Australia than in the
United States led of a lower level of expenditure because of their substantially lower level of remuneration; and that the larger number of doctor visits per capita were attained at a relatively low cost level.

Evidence available suggests that the level of health expenditure was not a good indicator of the volume of services provided per head of population. Health expenditures were a result of differences not only in the number of people employed but also their rate of remuneration. They also reflected, to some extent, the use of expensive technologies, the relative price paid for pharmaceuticals, as well as disparities in the costs of administration of the different modes of organisation in each country, and by implication the relative efficiency of each system in the pursuit of healthy lives.

\section{Health outcomes}

The United Nations Development Programme compiles a Human Development Index (HDI) that takes into consideration three factors of relevance to wellbeing: life expectancy, education and income.

Table 13: Human development index Australia, New Zealand, Canada, United States and United Kingdom, 2000 and 2011

\begin{tabular}{|l|c|c|c|}
\hline \multirow{2}{*}{ COUNTRY } & \multicolumn{2}{|c|}{ HUMAN DEVELOPMENT INDEX } \\
\hline \multirow{2}{*}{ Australia } & 2000 & 2011 & 0.032 \\
New Zealand & 0.898 & 0.930 & 0.033 \\
Canada & 0.874 & 0.907 & 0.042 \\
United States & 0,867 & 0.909 & 0.028 \\
United Kingdom & 0.883 & 0.911 & 0.038 \\
\hline
\end{tabular}

Note: The Human Development Index was adjusted for the 2015 edition of the Human Development Report and the data available was for 2000 and not 2001.

Source: UNDP. [26] Computations made by the author. 
The five countries made advances in the HDI in the period 2000-2011. Australia had the highest index value of 0.930 in 2011, among the five countries. This was only second to Norway in world ranking. It was the result of the longest life expectancy among the five countries, but also its level of education, and high income per capita that was second to the United States and close to that of Canada. The United Sates had the second highest value over the period that relied on the considerably higher income per capita, as life expectancy was below the other countries, and education was about the level of Canada and United Kingdom, but below that of New Zealand. Canada had the highest HDI advancement mostly due to a rise in life expectancy during the period. The United Kingdom had the second highest HDI advancement again due to a substantial improvement in life expectancy. The United States with the highest income also had the lowest life expectancy and the lowest gain in both the HDI and in life expectancy of the five countries (Tables 13 and 14). [26]
Longer lengths of life present risks of disability that tend to rise with age. Although, the estimation of disability years carries with it a number of assumptions, WHO estimates show that Australians continued to have the longest healthy life, free of disability, among the five countries of 73 years in 2012 and that the United States had the lowest at 70 years. The order of healthy life years was similar to that of life expectancy (Table 14).

The epidemiological transition has diminished premature deaths from communicable diseases and favoured noncommunicable diseases as the major cause of premature death in all five countries. The potential years of life lost due to premature death in Australia were the lowest among the five countries in 2012, with the lowest proportion of premature death due to infectious diseases. The United States by comparison had the highest level of premature

Table 14: Human development index, Australia, New Zealand, Canada, United States and United Kingdom, 2001 and 2011

\begin{tabular}{|l|c|c|c|c|}
\hline \multirow{2}{*}{ COUNTRY } & \multicolumn{3}{|c|}{ LE YEARS } & \multirow{2}{*}{ HLE YEARS 2012 } \\
\cline { 2 - 5 } Australia & 2001 & 2011 & INCREMENT 2000-2011 & 73 \\
New Zealand & 79.7 & 82.0 & 2.3 & 72 \\
Canada & 78.7 & 81.0 & 2.3 & 72 \\
United States & 78.3 & 81.5 & 3.2 & 70 \\
United Kingdom & 76.8 & 78.7 & 1.9 & 71 \\
\hline
\end{tabular}

Note: Le is the life expectancy at birth in years. HLE is the healthy life expectancy at birth in years taking into consideration years of disability. ${ }^{\circ}$ Source: OECD, [9] WHO. [27] Computations made by the author.

Table 15: Potential years of life lost and causes in Australia, New Zealand, Canada, United States and United Kingdom, 2012

\begin{tabular}{|l|c|c|c|c|}
\hline \multirow{2}{*}{} & \multicolumn{4}{|c|}{ YLL PER 1,000 PEOPLE } \\
\cline { 2 - 5 } & & \multicolumn{3}{|c|}{ CAUSE AS \% OF TOTAL } \\
\hline COUNTRY & ALL CAUSES & COMMUNICABLE & NON-COMMUNICABLE & INJURIES \\
\hline Australia & 119 & 5.0 & 83.9 & 11.1 \\
New Zealand & 126 & 5.9 & 81.5 & 12.6 \\
Canada & 138 & 6.8 & 82.5 & 10.7 \\
United States & 178 & 7.5 & 80.3 & 12.2 \\
United Kingdom & 161 & 7.4 & 86.3 & 6.3 \\
\hline
\end{tabular}

Note: YLL are the potential years of life lost at the age they occur due to premature death from the standard life expectancy, per thousand people. Communicable causes of death include infectious or contagious diseases, maternal causes, conditions arising during the neonatal period and nutritional deficiencies.

Source: WHO. [27] Computations made by the author.Source: OECD, [9] WHO. [27] Computations made by the author. 
deaths, as might be expected from its shorter life expectancy at birth, with also the highest level of premature deaths from communicable diseases and second highest level from injuries. New Zealand with a low level of premature deaths had the highest proportion of premature deaths due to injury, while the United Kingdom with a high level of premature deaths had the lowest proportion of deaths from injury (Table 15). These trends in injury as the cause of premature death point to social conditions as causes of premature death among young people, which was also part of experience in the United Sates.

However, the analysis of the potential years of life lost does not capture the years of disability implicit in the measurement of the years of healthy life (Table 14). WHO estimates of the four major causes of years of healthy life lost for the five countries were: neuro-psychiatric conditions, cancers, cardiovascular diseases and diabetes. This points to the importance of mental health to a healthy life that is not so apparent from the estimation of years of life lost due to premature death. Accordingly, the years of healthy life lost due to disability was highest in relation to neuro-psychiatric conditions. [28]

The health outcomes indicators in the analysis are averages for populations that gloss over differences among socioeconomic groups within the five countries. In the first instance, there are differences in health and life expectancy between first settlers and the people who came afterwards in Australia, New Zealand, Canada and the United States. [29] The gap of 4 years in life expectancy between American Indians and Alaska Natives and that of all races in the United States, in 2007-2009, was the shortest in the four countries. [30] The gap in Canada was in the range of 6 to 14 years, in 2001, depending on the particular indigenous group, being largest in the case of the Inui people. [31] The difference in New Zealand between the Maori and non-Maori population was 7 years in 2010-12 [32]. Australian Indigenous people had the largest gap of 11 years in 2010-12. [33]

There is also evidence of significant inequalities in health and life expectancy between socioeconomic groups. The information available follows various approaches in the classification of these groups in different countries and is expressed in different ways. In the United Kingdom (England and Wales), studies of life expectancy of five social classes showed that there was a gap of seven years in life expectancy between the top and the lowest social class in 2002-2005, for both males and females. This gap was only slightly smaller than that observed in 1997-2001. [34] In Australia, according to an Index of Relative Socio- Economic Disadvantage based on income, education, employment and occupation, mortality in the lowest quintile was $29 \%$ higher than in the highest quintile in 2009-2001; and potential life lost due to premature death was 1.8 times higher in the lowest than the highest socioeconomic group. [35] In Canada, a study of inequality in health and mortality found that, in 2011, people in the lowest income quintile suffered from higher rates of illness, and especially mental illness which was twice as high in the lowest than in the highest income quintile. Infant mortality rates were also about 1.6 higher in the lowest than the highest income quintile. [36] In the United States, estimates of life expectancy according to race showed that Black/African American people had a life expectancy about four years lower than White people in 2011. [10] Limitations in usual activities due to chronic conditions affected $21 \%$ of people whose family income was less than $\$ 35,000$ but only $9 \%$ of people in families with incomes of $\$ 35,000$ or more in 2011. [37]

Thus, in spite of some progress made in health outcomes made in each country, there continue to be substantial inequalities associated not only with Indigenous and nonIndigenous people but also with people in different socioeconomic strata.

\section{Choices and challenges}

Australia and the other four countries exercised choices that focused on health services mostly concerned with the return to health after illness or trauma. With the possible exception of the lower use of tobacco, which has and no doubt will have an impact on healthier lives, health systems have not succeeded as well in reducing risk factors that have a cumulative, deleterious effect on healthy life. These are often associated with behaviours and social conditions that health systems give lower attention and priority to.

Given the focus on the management of illness and trauma, the five countries differed in how they organised and used their resources to produce effective health services with different efficiency and equity. Among the five countries, Australia employed the highest number of nurses and medical practitioners per head of population to generate the second highest number of hospital inpatient admissions and medical practitioner visits. This was associated with the lowest level of health expenditure as a proportion of GDP among the five countries. This implies a high level of efficiency in the production and access to health services and resulted in a low proportion of administrative costs. However, these results were achieved by lower use of some costly medical technologies and lower remuneration rates of medical practitioners. 
Australia and Canada tend to use similar organisational set ups to provide core health services, with universal coverage, but differed substantially in the use of doctor and hospital services, with Canada making greater use of doctor visits per head of population while using less inpatient services. In this regard, one factor was the lower use of private hospitals in Canada than in Australia. Canada also spent more on pharmaceutical drugs and made more use of expensive technologies than Australia, and these had an influence on the higher level of health expenditure as a proportion of GDP in Canada. Health outcomes in Canada in terms of life expectancy made relatively more progress than in Australia. However, they still lagged slightly behind Australia in 2011, including a larger potential years of life lost due to premature death.

New Zealand and the United Kingdom provided core health services, with universal coverage, through national health organisations with relatively low administrative costs. They employed about the same lower number of doctors per head of population, lower than Australia, but differed considerably in the ratio of nurses employed. This was associated in New Zealand with the highest rate of hospital inpatient admissions but a considerably higher relative rate of doctor visits in the United Kingdom, with the same ratio of doctors per capita. New Zealand also made the lowest use of expensive medical technologies and spent less on pharmaceutical drugs as a proportion of GDP than the United Kingdom, and the other three countries. The United Kingdom life expectancy rose faster than other countries, not including Canada, to achieve the same level as New Zealand's in 2011.

The United States experience is unique among the five countries. It was the country without universal coverage of core health services and relied on a patchwork of public financed coverage for old people and the poor, and private funding of access to health services. The higher costs of administration of private health insurance led to the highest administrative costs among the five countries. Its access and use of hospital inpatient services was the lowest after Canada and doctor visits were also the lowest after New Zealand. However, it spent more on pharmaceutical drugs as a proportion of GDP than any other country, used more expensive technologies and paid more to its medical practitioners and nurses than the other countries. This resulted in the highest level of health expenditure as a proportion of GDP and was associated with the lowest life and healthy life expectancies among the five countries.
The analysis of health outcomes and factors associated with them in the five countries illustrates choices made and challenges to be faced. It is apparent that spending more did not necessarily lead to better outcomes or services rendered. The five countries experience point to the importance of the relative efficiency in the application of human resources in health care and their productivity, regardless of their level of remuneration. It shows the relative importance of public funding to achieve universal coverage of core health services, and that public funding did not result in higher administrative costs or higher levels of expenditure on health services as a proportion of GDP. An important challenge to be faced is bridging the gap in healthy lives between indigenous and other people in the United States, Canada, New Zealand but especially Australia. Further, it confirms the results of choices made in relation to the low attention given to behaviours and social conditions that impact on healthy lives and have kept some social groups at a disadvantage. This poses a challenge to the health system in the attainment of healthier lives.

\section{References}

1. Martins JM, Isouard G. An evidence-based framework: competencies and skills for managers in Australian health services. A Pac J Health Manag. 2015;10(2):8-23.

2. Shaw M, Dorling D, Smith D. Poverty, social exclusion, and minorities. In Social Determinants of Health. Marmot M, Wilkinson RG, editors. Oxford: Oxford University Press; 1999.

3. World Bank (WB). GDP per capita, PPP (constant 2011 international \$) [cited 8 October 2016]. Washington DC; 2016. Available from: http://data.worldbank.org/indicator/NY.GDP.PCAP.PP.KD

4. Organisation of Economic Cooperation and Development (OECD). OECD Better Life Index 2103 [cited 8 October 2016]. Paris; 2013. Available from: www.oecd.org

5. World Health Organization (WHO). Noncommunicable Diseases Country Profiles 2014. Geneva; WHO: 2014.

6. World Health Organization (WHO). Global status report on noncommunicable diseases 2014. Geneva; WHO: 2014.

7. Australian Bureau of Statistics (ABS). Participation in sport and physical recreation 2009-10. Canberra; ABS: 2010.

8. Australian Bureau of Statistics (ABS). Profiles of Health, Australia, 2011-13. Canberra; ABS: 2013.

9. Organisation of Economic Cooperation and Development (OECD) [cited 30 September 2016]. OECD.Stat. Paris; 2016. Available from: www.oecd.org

10. U. S. Department of Health and Human Services (DHHS). Health, United Sates, 2015. Washington DC; DHHS: 2016.

11. Australian Bureau of Statistics (ABS). Australian social trends, April 2013. Doctors and Nurses. Canberra; ABS: 2013.

12. Organisation of Economic Cooperation and Development (OECD). Health at a glance - OECD indicators 2003 [cited 30 September 2016]. Paris; 2003. Available from: www.oecd.org

13. Organisation of Economic Cooperation and Development (OECD). Health at a glance 2013 [accessed 30 September 2016]. Paris; 2013. Available from: www.oecd.org 
14. Organisation of Economic Cooperation and Development (OECD). OECD. Health Data 2013 [cited 30 April 2014]. Paris; OECD: 2014. http://stats.oecd.org/Index.aspx? DataSetCode=HEALTH_PROC.

15. Ministry of Health, New Zealand (MOHNZ). Hospital Events 2007/08. Wellington; MOHNZ: 2011.

16. Ministry of Health, New Zealand (MOHNZ). Publicly funded hospital discharges - July 2010 to 30 June 2011. Wellington; MOHNZ: 2013.

17. Ministry of Health New Zealand (MOHNZ). Privately funded hospital discharges - July 2010 to June 2011. Wellington; MOHNZ: 2013.

18. Australian Institute of Health and Welfare (AIHW). Australian hospital statistics 2000-01. Canberra; AlHW: 2002.

19. Australian Institute of Health and Welfare (AlHW). Australian hospital statistics 2010-11. Canberra; AlHW: 2012.

20. Pharmaceutical Benefits Scheme (PBS). Expenditure and prescriptions. Canberra: Department of Health and Ageing; 2012.

21. Australian Institute of Health and Welfare (AlHW). Health expenditure Australian 2012-13. Canberra; AlHW: 2014.

22. Canadian Institute for health Information (CIHI). National health expenditure trends, 1975 to 2014. Ottawa; CIHI: 2014.

23. Ministry of Health (MOHNZ). Health expenditure trends in New Zealand 2000-2010. Wellington; MOHNZ: 2012.

24. Fujisawa $R$ Lafortune $G$. The Remuneration of general practitioners and specialists in 14 OECD countries: what are the factors influencing variations across countries. Paris: OECD.

25. Organisation of Economic Cooperation and Development (OECD). Remuneration of doctors and nurses: progress and persisting issues. Joint session of health Data Correspondents and Health Accounts Experts, 17 October 2013. Paris.

26. United Nations Development Programme (UNDP). Human Development Report 2015. New York; UNDP: 2015.

27. World Health Organization (WHO). World health statistics 2014. Geneva; WHO: 2014.

28. World Health Organization (WHO). WHO country statistical profiles: Australia, Canada, New Zealand, United Kingdom and United States [cited 8 October 2016]. Geneva; WHO: 2016. Available from: www.who.int

29. Martins JM. Left behind: the survival of Australian Indigenous people. Sydney: Australian College of Health Service Executives; 2002.

30. US Department of Health and Human Services (DHHS). Life Expectancy - American Indians and Alaska Natives, Data years: 2007-2009. Rockville MD; DHHS: 2014.

31. Statistics Canada. Projections of the Aboriginal Populations, Canada, 2001 to 2017. Ottawa; Statistics Canada: 2005.
32. New Zealand Statistics. New Zealand Period Life tables 2010-12 [cited 15 October 2016]. Wellington; 2013. Available from: www. stats.govt.nz/browse_for_stats.aspx

33. Australian Institute of Health and Welfare (AlHW). The health and welfare of Australia's Aboriginal people and Torres Strait Islander peoples 2015. Canberra; AlHW: 2015.

34. Department of Health (DOH). Tackling Health Inequalities: 10 Years on. London; DOH: 2009.

35. Australian Institute of Health and Welfare (AlHW). Australia's health 2016. Canberra; AlHW: 2016.

36. Canadian Institute for Health Information (ClHI). Trends in Incomerelated Health Inequalities in Canada. Ottawa; CIHI: 2016.

37. US Department of Health and Human Services (DHHS). Summary Health Statistics for the U.S. Population: National Health Interview Survey, 2011. Hyattsville MD; DHHS: 2012. 